\title{
A study on change in behavioral pattern with reference to the select novels of AmitavGhosh
}

\author{
Dr.Sreela.B ${ }^{\mathrm{a}}$, Dr.SreejaBalakrishnan ${ }^{\mathrm{b}}, K_{\text {.PoornimaVaralakshmi }}{ }^{\mathrm{c}}$ and Yamini $\mathrm{P}^{\mathrm{d}}$ \\ A \\ RajaLakshmi InstituteofTechnology, AssistantProfessor,Chennai, India \\ ${ }^{\mathbf{b}}$ AvinashilingamInstituteforHomescienceand HigherEducationforWomen, \\ AssistantProfessor, Coimbatore,India \\ c,d SriSairamInsitituteofTechnology,AssistantProfessor,Chennai, India.
}

ArticleHistory:Received:11January2021;Accepted:27February 2021;Publishedonline:5April2021

\begin{abstract}
This article is an attempt to illustrate the different ways through which culture gets transformed as a result of contactwith other cultures. The desire to gain sociability forms ground for cultural changes such as accultration, assimilation, diffusionand other types of cultural changes. Amitav Ghosh is a prolific writer who occupies an invincible space among the national andalso the international writers. Six of his novels are analysed to study the changes in the behavioral patterns of the characters inthenovel.Cognitionisamightyfactorthatconditions thethoughtsofeveryhuman.Thedesiretogarnersolidarityandestablishsociability is the chief reason for cultural compromises. Therefore, Georg Simmel's theory on sociabilities is taken into accountto support this study.
\end{abstract}

Keywords:Cognition,hybridity,identity,tolerance,acceptance,solidarity,language,codemixing,codeswitching,hegemony

\section{Introduction}

Theworldisanintricatefusionofdifferencesandthismultifacetednessmakesitsophisticatedandincomprehensible.U niformitywoulddeprivetheworldofasocialstructureandsuchaworldbereftofdifferencesis inconceivable. It is pretty obvious that people in different regions acquired different cultural, religious andlingual practices naturally and consequently they differ from region to region and nation to nation. The languageone speaks and the dress he wears and the way he prays and all such factors are bequeathed from one generationtoanother.Inthebygonedaysthereweren'tanyneedormeanstocommunicatewithpeopleofanotherrace. With all the explorations and the advancement in science and technology, people of different nations meetandcorrespond and as a result, each one becomes aware of the differences in their cultural, lingual and customarypractices. These meetings harbor different colours of emotions among different groups. At times, people tend toview the practices of other races with contempt. This contempt leads to hatred, conflict and restiveness theworld.Ontheotherhand,education, experienceandnecessitygoadpeopletoacceptdissimilarities, wherebynewidenti tiesare born.

Collective effort shall bear fruit only when the group ties up and support each other. A sense of oneness isconceived when people of similar backgrounds and ideologies congregate. Civilization is generally allied withculture and any ritual or practice that shocks the human conscience is ridiculed as barbaric and savage. Whereassocial and cultural anthropologists are impartial and therefore the practices of all the nations, regions, continentsand ethnicity are defined as culture. This paper aims to identify the ways through which one acquires culture andthe way it gets transformed. Cultural changes take place in different patterns depending on the flexibility of thefollowers. Of course, there are iron curtained nations where such changes are strictly a taboo. The East-Westencounter is nothing new; it has been a part and parcel of the society since the explorers discovered new lands.Explorationresultedincolonization,followedbyslavery,trade,immigrationandsoontotherecentglobalization. As a matter of fact, cultural changes were the cause outcome. The factor that provokes change is the craving toaccomplishsociabilityandsolidarity. Thedegreeoffriendlinesstypicallyfoundamongmembersofagroup, nationor society is called as sociability. The degree to which people in a community, nation or society share a commonunderstandingofthetasksandgoalsiscalledassolidarity. Thesenseofsociabilityandsolidarityhasexistedsincet he birth of humans. These shared notions extended with the growing socioeconomic influence. While seaexplorations marked the beginning of cultural sociability, it took different forms and names such as globalization,immigration, diasporasandmanymore. Thechangesthathavetakenplaceduetotheinfluenceoftheaforeme ntioned factors have made sociology an interesting subject.Therefore, 'society' is the protagonist of thisstudy.

\subsection{TheTheoryofSociabilities}


George Simmel (1949) in his work The Sociology of Sociabilities has made a journey in search of thenucleusoftheformationofsociety.Asperhisview"theimpulsesandinterest, whichamanexperiencesinhimselfandwhi chpusheshimouttoothermen,bringaboutalltheformsofassociationbywhichmeresumofseparatearemadeintoa 'society'( 254).Notwohumansthinkalike, buttheprocessofthinkingofallhumansisidentical.AdolfBastainisaBremenbornanthrop ologistwhoishonouredwiththetitleof'fatherofGermananthropology'.Hehaspromulgated the concept called "psychic unity of mankind" wherein he states that every human mind function inthe same way regardless of race and culture as "every human mind inherits a complement of species-specific'elementary ideas" (1983). Several other anthropologists and sociologists endorsed his theories and few amongthem are Franz Boas, Edward Taylor, and Carl Jung. Jung formulated his theory of archetype and collectiveunconscious grounding on Bastian's concept. Sreela. B in her article titled "Mimicry as the play-form of life in theselectnovelsof AmitavGhoshhasstated

Endorsing one another in a society is a man-made process intended to acquiresupportandithasculminated in the configuration of a collection of cultures, religions, languages, and customs in the world.Human intelligence and perceptions cultivate societies and humans all over the world display identicalthought process due to the homogeneity of the species called Homo sapiens. The lives of humans areinextricably interconnected with each other. The collectivity of their lives, experiences, norms, culture,ethics, beliefs, customs, religion, conflicts, and several such factors form the foundation of sociability andsolidarity (2015).

Family and society are inter-reliant as everyone acknowledges that families construct the society. However,once formed, it is the society that dictates the family of what to do and what not to do. The societal ground rulesmanipulate the thoughts, beliefs and attitudes of every entity which are dispensed to the family and subsequentlypassed on to the larger circles and the next generation. The cultural patterns which every nation follows today aremetamorphosed versions of their authentic culture. Throughout history, humans have changed their customs, beliefs, habitssoastosuittheirchangingneeds.Consequently culturesmeetandonesuchoutcomeislabeledasEast-Westencounter which has been a hot topic in several writings by Indians. Sociability is the quality of being sociable,affable and gregarious. This gift is obligatory for a harmonious living in the society. It is these associations thatfacilitatepeople toinstitutecomradeshipinthe globalized world.

Differentmanifestationsofculturaltransformationsarechristenedasacculturation,diffusion,transculturation, andassimilation.Alltheseformsofhybridizationsarebornoutofman'sdesiretopsychologicallyunite with the society. Winthrop suggests that "this change is brought about under conditions of direct contactbetweenindividualsofeachsociety”(1991)."Individualsofaforeignorminorityculturelearnthelanguage, habits,a ndvaluesofastandardorthedominantculturebytheculturalprocessofacculturation. The

processbywhichtheseindividuals enter the social positions, as well as acquire the political, economic, and educational standards of thedominant culture is called assimilation. These individuals, through the social process of assimilation, becomeintegrated withinthe standardculture" (Thompson,1996).

Cognition, environment, and society influence the thought process of humans unfathomably. In otherwords, thoughts are encoded from the data of experience. Being a social anthropologist, Ghosh has visited manynations in search of its roots and ramifications. Influenced by these travel experiences, Ghosh blends his imaginationwith realism and consequently his novels exemplify the means of cultural hybridization. There are a few episodesin the novels of Ghosh that validates John Locke's 'Tabula Rasa' theory, wherein he compares the human mind toa blank slate which is encoded by nature. This theory is otherwise termed as 'nature vs. nurture' as it affirms therelationship between environs and humans in shaping his thoughts and perceptions. All human beings habituallyfollowthepracticeswhichtheyinheritfromtheancestorsandfollowitsincetheirchildhood.Naturally, theybelie vethat their practices are the right way of living. In the lives of many individuals, customs, practices and cultureoverpower the idiosyncrasies of every individual. Defying cognition, few people decree themselves as egalitarianshavingnoregardforreligious,racialandsuchotherdifferences. Itissounfortunatethattheyrecognizetheiraffini tyforall those attributesonlywhensituationswarrant.

\section{MulticulturalisminGhosh'snovels}

Amitav Ghosh belongs to the literary tradition that was nurtured and nourished by Rushdie and others.Likemanyofhiscontemporaries, heismassivelyinfluencedbythepoliticalandculturalmilieuofpost-

independentIndia. He is a multicultural, multi-geographical and also a historical writer.He selects his characters from everycorner of the world and does an in-depth research on history and various other arenas which are to be dealt in hisnovels. His adeptness at deciphering the psychology of the characters is palpable in all his novels and readers

finditawe-

inspiring.AmitavGhoshhasdefinitelyattainedunparalleledsuccessamongtheprominentIndianWritersinEnglish. His novelty in the use of language has received critical acclaim. "Loss of Homeland" is the predominantthemeincolonialaswellaspostcolonialnovels. Thesenseofnotbelongingtotheplacewheretheybelongtoresu ltsin major societalchanges.

Sea of Poppies is a very popular novel by Ghosh grounded on the Indo-China war on opium trade. ThisnovelformsapartoftheIbistrilogy.Neel,thedethronedZamindar(landlord)inGhosh'sSeaofPoppiesisan 
example of how these three elements overpower 'Man'. Neel wonders at his own hatred towards food cooked byunknown handsduringhisimprisonment:

Neel had always taken pride in laying claim to his lineage of egalitarianism, all the more since it was hisprerogative to sit on a Raja's gudee: but why, then, had he never before eaten anything prepared byunknown hand? He could think of no answer other than ease of habit: because he had always done whatwas expected of him; because the legion of people who controlled his daily existence had seen to it that ithappened in that way and no other. He had thought of his everyday routines as a performance, a duty andnothingmore;oneofthemany littleenactmentsthatwererequiredbythedemandsofsocialexistence,... it was just an illusion, no more than a matter of playing a part in the great charade of conducting ahouseholder'slife. (2008)

In the novel In An Antique Land, an ardent Muslim named Ustaz Mustafa compels the staunch Hindunarrator to go to the Mosque with him and join their prayers. The narrator is reluctant to join them and Ustaz Mustafaflees from the spot as soon as he hears the call for prayer from the mosque. The narrator himself deliberates on thereasons for his reluctance. The irony is that the narrator has visited the land for the purpose of learning originandcultureofthatland."Butwhenthemomenthadcome,I'dknownthatIwouldn'tbeabletodoit:Ihadbeentooafraid,a nd forthelifeofme Icould notunderstandwhy"(Ghosh, 2006).UstazMustafa isnotreceptiveofanotherreligion and he believes that his God and method of worship is infallible. On the other hand, the narrator himself ispsychologically inhibitedandvehementlyrefusestoworshipanunfamiliar God.

Paulette in Sea of Poppies, Ila in The Shadow Lines, Dolly, the exiled Princesses and Arjun in The GlassPalace typify the environmental process on which culture is grounded. All these characters endure identity crisesin the land where they belong as well as in the land where they are fostered in. They represent the displaced anduprooted community who are in search of their centre. Paulette is the daughter of a French botanist named PierreLambert. She is born in the dinghy owned by Jodu's father. Paulette's mother dies soon after the child birth andJodu'smotherbecomesherwetnurse.Thereafter,sheisbredimbibingallBengalitraditionsandJodubecomeshersiblin g. "As for Paulette, the first language she learnt was Bengali, and the first solid food she ate was a rice-and-dal khichri cooked by Jodu's mother. In the matter of clothing she far preferred saris to pinafores" (Ghosh, 2008).It is this adaption of Bengali culture that makes her life miserable at the house of Mr. Burnham, who adopts herafter the demise of herfather.

TheShadowLinesisanovelinwhichculturaldifferencesshapeoneofthemajorthemes.Ila,thenarrator'schildhoo $\mathrm{d}$ friend and with whom he is in love becomes the horizon of cross-cultural confrontation. She is a BritainbredIndianandthereforeshehabituallyfollowsthecultureofherhostcountrywhichisfrowneduponbythepeopleof her native land. She holds no desire to return to her native soil as she finds it hard to adapt to the culturalconstraintsinIndia.Asianshavealwaysdictatedstintregulationsonwomen'sbehaviour,culture, anddress. Onthec ontrary,westernnationsgiveroomforlibertyofwomen.Ilafindsthewesternmodeoflifemorefeasibleandcozy.She states the reason for her unwillingness to the narrator in the following words. "It's only because I want to befree.Freeofwhat?Isaid.Freeofyou!Sheshoutedback.Freeofyourbloodycultureandfreeofallofyou"(Ghosh,1988).

Cultureisconveyedthroughdifferentmediumofcommunication:"Culture[consists]oflearnedsystems of meaning, communicated by means of natural language and other symbol systems, having representational,directiveandaffectivefunctions, andcapableofcreatingculturalentitiesandparticularsensesofreality"( D'Andrade, 1988). Cognition in humans is conscious and unconscious, concrete or abstract, as well as intuitive(like knowledge of a language) and conceptual (like a model of a language). Cognitive processes use prevailingknowledgeandbreednew knowledge.

DollyinTheGlassPalaceiswellaccustomedtothepracticeofShiko(prostrating)whileenteringtheroomoftheKin gandtheQueen.SimilartoDolly,allothermaidswhoarebroughtupintheGlassPalacearequitetunedthe rituals of reverence. After the deportation of the royals, all the maids, except Dolly return to their homeland. Inorder to assist them in daily chores, Indians are hired and are forced to imitate all the rituals of shiko and walkingon the fours. Habituated to the rules and practices of Burmese royals, Dolly does not realize the reason behind thedifficultyofothermaidsinfollowingthem. ThepracticeswhichDollyfindstobeabsolutelynormalareconsideredbizarre bythepeopleofanothernationalityandculture."Toheritseemedmucheasierthanhavingtostandupeverytimeyouwantedto dosomething.Itwasmuchmorerestfulthisway:whenyouweren'tdoinganythinginparticularyou couldrelaxwith your weightonyour heels" (Ghosh, 2000).

\subsection{HybridityofCultures}

Dolly exemplifies the process of diffusion where the cultural aspects of two different cultures blend. SheexhibitstheinfluencebyIndiancultureduetothelongstayinIndia. WhileRajkumartakesDollywithhimtoBurmaon the ship he introduces her to his mentor Saya John.Unconsciously she joins her hands together in the Indianway to pay Saya John her respects. This moment in the novel testifies the impact of the environment and cognitionin the cultivationof culture andrelatedpractices.

A British midwife named Mrs Wright is appointed to support the Queen during her period of pregnancy.ShedeniesvehementlytoshikointhepresenceofQueen.TheQueenmakesthisappealtoMr.Cox, apoliceofficer 
who is given the charge of the royals and his response only disappoints the Queen. "She could bow, he said, fromthewaist,butsheneedn'tshikoandcertainlywouldn'tcrawl.ShewasanEnglishwoman"(Ghosh,2000).Likewisethe BritishersrefusetofollowtheMandalayprotocolandtheQueenmakesitapointnottoacknowledgetheirentryand thevisitorsare expectedto take the lowchairsaroundHer Highnessthemselves.

Education is a dominant phenomenon in relegating culture to the learners. Educating the colonies was ashrewd decision of the colonizers through which they found success inmultiplying the adorers of Western culture.Arjun is a prominent and complex character in the novel The Glass Palace. Arjun is the nephew of Uma and

he

classfamily.AlthougheducatedinIndia,thesystemofeducationthatwasfollowedin oneintroducedbytheBritish.

UnlikePauletteinSeaofPoppies, Arjunisateaseinbehavingwesternashehaslearnedtodancethetangoandtoeatro astbeefwithaknifeandfork.HegrowsupandservesintheBritishIndianarmyandduringtheSecondWorld War; he is haunted by the thoughts of his own identity. A group of Indians in the British Indian army planstobecomerenegadesandhelpJapantovanquishBritain, whichwouldresultintheliberationofIndia.AnanglicizedIndi an nicknamed Hardy persuades Arjun to join the group and contribute to the liberation of India. But thousandsof questions on identity bombard him and he is perplexed, not knowing to whom to render his support to. He isawarethat"exceptforthecolorofourskin,mostpeopleinIndiawouldn'tevenrecognizeusasIndiansWe

wanted to be sahibs and that's what we've become." He is not sure that "we can undo all of that just by putting up anewflag"(Ghosh,2000).Histhoughtprocesshasbeensteeredinsuchawaytosupportwesternization. Throughoutthe novel he seems to be an ardent supporter of the British and only towards the end of the novel he returns to hisnativity,oncethe layerofdelusion meltshe recognizesthe bitterfacts.

\subsection{LanguageandCulture}

Languages play the dual role of creating sociability and also the medium to express solidarity. "Languageisanindicatoraswellasaprotectorofidentity.Communicativepotentialandpowerofthelanguageistoanextentt hat it has been considered as the most important and significant element of solidarity" (Habermas, 1979). Especiallyamong the migrants, language remains an effective tool to solidarity. Ghosh in his novels introduces the readers toseverallanguagesbothnationalandinternational.Codeswitchingisaverycommonandeffectivemeanstoestablishrapport and earn solidarity. However, their love for their mother tongue remains intact and is palpable when theyhappen to meet their own lingual counterparts. The day when Tha'mma meets Mayadebi epitomizes their longpreservedlovefortheirdialect.Ontheirarrival"Mayadebijumpedoutandsheandmygrandmotherhurriedtowardseachothe rand embraced,laughing,andtalkingquickly inthatlanguagethatnoneofuscould understandproperly,their oldDhaka dialect" (Ghosh, 2004).

InTheCircleofReason, Ghoshportraysthevillage 'Lalpukur'astheabodewhererefugeesfloodedduringthe war time. He emphasizes the potential of language by narrating how the migrants in Lalpukur village cherishtheirtongue.Theytakeprideinthecomplexityoftheirlanguagewhichmakesthenon-

nativelistenersgounawares. The migrants speak the language of their host land to gain an identity in their new land yet they sustain the love oftheir language intheirownway. For instance:

Most of the people of Lalpukur belonged originally to the remote district of Noakhali, in the far east ofBengal close to Burma. They had immigrated to India in a slow steady trickle in the years after East Pakistan becameEast Pakistan. Most of them left everything but their dialect behind. It was a nasal sing-song Bengali, with whoknew what mixed in of Burmese and the languages of the hills to the east? Many of them had learnt the speech ofWest Bengal, but it had only made their own dialect dearer to them — as a mark of common belonging... (Ghosh,1986)

The emigrants thereby ascertain solidarity with the natives of the village in Lalpukur and simultaneouslypreservetheirethnicidentitybyretainingtheirdialectamongthemselves.Learningthelanguageofthehostc ountryis definitely an effective means to seek the acceptance of people of different races. In The Hungry Tide, Nilimarecounts the pathetic conditions of the Dalits (caste based untouchables) after the partition of Bangladesh. Thepoorest of the rural people were exploited by the religious fanatics and consequently they were sheltered in aresettlement camp in central India. The camp was more like a concentration camp with no means to escape and"theycouldnotspeakthelanguagesofthatareaandthelocalpeopletreatedthemasintruders, attackingthem withbows,arrowsandotherweapons"(Ghosh,2004).AjuxtapositionoftherefugeesinLalpukurandBangladeshprovesthe importanceofadaptationoflanguage.ThepeoplewhosettleinLalpukuradapttochangesforsurvivalwhereasitisthe inability of therefugeesinBangladeshtoadapttochangethatresultin theirownpredicament.

In the novel The River of Smoke, Ghosh delineates the sense of pride and the love in which the Chinesepreserve their language, culture and food. Britain had faced a lot of hurdles while trading with China. The Chinesebelievedthattheywerethemostsophisticatedsocietyandtheirfood,customsandproductsweresuperiortothatofot hernations.TheChinesewereadamantabouttheircommunicationsbeingpurelyinChinesewhichtheBritishersnever paid any heed to. Consequently, the trade between China and Britain was in many cases hindered by theChineseprotocol."IfthereisanynationthatcanmatchtheEnglishintheirarroganceandobstinacy,itissurelytheChinese " (2011). Howard Giles,Vikki Katz, and Paul Myers in the book titled Language Attitudes and the role 1192 
ofCommunityhasstatedthat: 
Ourviewsofothers, includingtheirsupposedbeliefs,capabilities, andsocialattributes,canbedeterminedin part by influences derived from our perceptions of their speech characteristics and language varieties.Indeed overt responses and communications to speakers as well as important social decisions regardingtheir prospects and welfare can be meditated by our so-called 'language attitudes. These in turn can affectourself-presentationsasweattempttoshapeothersreactionsto usand their attributionsofus.(2006)

Codemixing andCodeswitching canbetermed aschutnification inthewordsofSalmanRushdie.Peoplehave a tendency to speak the language of the most powerful sector of the society; thereby they intend to elevatethemselves in social status. Sea of Poppies is a multilingual and multidialectal novel and code mixing is rampantthroughoutthenovel.Bhojpuri,Bengali,English,Frencharethelanguagesthatarecodemixedandcodeswitched.T he language of the crew members of the ship is quintessential of code mixing and also switching of languages.English readers would find this novel trying their patience as code mixing hinders the comprehensibility of thenovel.Every crew membermixeshismothertonguewithEnglish inordertocommunicate.

'MalumZikri! Captain-bugger blongi poo-shoo-foo. He hab got plenty sick! Need one piecedokto. No one can chowchowtiffin. Allotimdochheechhee, pee-pee.PlentysmelliinCaptin cabin.'(Ghosh,2008)

In The River of Smoke, the inmates of the ships carrying opium who anchor at Hong Kong create a newworldforthemselves. "EventhoughthemajorityofHongKongChinesearenativespeakersofCantonese,Englishhas always played an important role in the government, education and employment" (Luke, 1982). Language andfood adaptations are the major step they take when they accept change. Chai becomes the favourite drink andsamosa,themostrelishedsnack.ButtoNeel,thesoundoftheunfamiliarwordsisjusttastefulastheitemsthatboretheir names. "He found that he was constantly learning new words from others in Bahram's entourage: some, likechaicamefromCantonese, whileothersbroughtitfromthePortugeseby

Vicolike 'falto'forexample,meaningfraudulent or false which became phalty on Schha tongues" (Ghosh, 2011). Bharam Modi's extramarital relationshipwith Chi-mei is also aided by lob-pidgin and that proves how the man - woman relationship crosses all lingualbarriers.

The colonizers were successfully making the colonies believe that they were the best refined nation withthebestsophisticatedculture.Asaresult, theelitiststartedadaptingthecultureoftheWhitestoportraythemselvesasasu periorrace.ArjuninTheGlassPalace whoendeavourstojointhegroupoftruemodernIndiansadoptseverypossible way of imitating the West. At Howrah station, while Dinu and Arjun meet, Dinu notices an unbelievablechange in Arjun. From a drowsy person, he has changed a lot especially his patterns of speech have undergone anoticeable difference. His speech consists mainly of jargons with a mix of English and Punjabi slang and everyoneis"eithera 'chap'or a'yaar"'(Ghosh,2000).

PredominanceofEnglishinvariouspartsoftheworldreiteratesAntonioGramisci'sconceptofhegemony. “Throu ghouthumanhistory, thefateoflanguageshasbeencloselylinkedtopoliticalpowerrelationships.Politicalshifts in the international system continue to affect linguistic patterns, which today are still in a state of fluxfollowing the end of the Cold War" (Maurais,2004). People have a tendency or rather are left with no other choiceother than surrendering their individuality in favour of power, authority and financial superiority. Colonization ofthe powerless countries and the subsequent subservience exhibited by the colonized are good examples of theinfluence of power. The tendency to follow the policies of the powerful sector by the less privileged results inidentity-based complexities which get manifested in various forms. Accepting a foreign tongue and trying toreproduceitisalso a formofsubservience tothe power.

ThepopularityofEnglishinothercountriesisanexampleofhowpowercangoadpeopletoacceptlingualshift.

English is the lingua franca in many third world countries and this validates the influence of power in othernations. The education system in India lays emphasis on English language learning, which is chiefly because ofpowerful position held by the U.S.A. Moreover, in a multi-lingual country like India people find the existence oflingua franca a convenient tool for communication. There are several instances in Ghosh's novels where languagebecomes a bridging force between people of different nations whereas for the Zamindar of Rashkali, Raja NeelRattan the ability to comprehend and reciprocate the language of the colonists abets to his plight inside the prison.He is frowned upon by the English while he speaks English. The captivity of Neel and the humiliation he faceswhenever he utters English testify the theory of Homi. K. Bhabha of mimicry and hybridity. Mimicry in colonialand postcolonial literature is most commonly seen when members of a colonized society (say, Indians or Africans)imitate the language, dress, politics, or cultural attitude of their colonizers (say, the British or the French). In thenovel Sea of Poppies, the author portrays Neel as a person who has mastered the tongue of his master. However,thedrivingforcebehindeveryactofmimicryisassociationwith people ofanotherrace

The old Raja had always got on well with Englishmen, even though he spoke their language imperfectlyand had no interest at all in their books. As if to compensate his own limitations, the Raja had hired aBritishtutorforhisson,tomakesurethathehadathoroughschoolinginEnglish...... Neelwaslittlefittedfor the company of such means, Mr. Burnham and they in turn tended to regard him with a dislike thatbordered oncontempt. (Ghosh,2008)

This contempt prevails throughout the novel where the Britishers find it difficult to stomach the reality of Neelspeakingtheirlanguageandhisfamiliaritywiththeirliterature.SoonaftertheregularstripsearchofNeel,he 
questions the jailor in English for which he faces severe abuse. "The man's eyes flared and Neel saw that he hadnettledhim,simplybyvirtueofaddressinghiminhisowntongue.......anintolerableinsolenceinanIndianconvict,adefi lementof the language"(Ghosh,2008).

TheWhitesnotonlydislikedtheideaofnativesmasteringEnglishbutalsofearedtheconsequencesoftheWhites going native. They considered themselves to be the only civilized race in the globe and hence the culturesof other nations were averted. As Mr. Doughty tells Zachary, "Mind your Oordoo and Hindee doesn't sound toogood: don't want the world to think you've gone native" (Ghosh, 2008). There is a curious version of this fear inthe native's mind too. It is best exemplified in the pressure built upon the Europeans regarding the behaviour anddress code they were expected to observe without any margin for deviation. The white man had to shoulder hissacred burden. It was a sacrifice that he had to make. He had to colonize, control, exploit, tyrannize and even killthe black/brown/yellow peoples of the world, in order to civilize them. The white man's arrogance is reflectedunconsciously in the smallest of things. During Neel's trial, the judge declared that India had been "opened

thebenefitsofcivilization...[theEnglishmenwere]chosentoburdenwiththewelfareofsuchracesaswerestillintheinfancy of civilization"(Ghosh,2000).

\subsection{CulturalHybridityinReligion}

Every nation with a profound legacy, treasures its myth, folklore, customs and practices. "Sundarbanrepresents a society that is primarily agricultural. The people live in villages adjoining forests which are

homeofTiger.Forsurvival,thesepeoplehavetofightwiththenaturedayinanddayout.Thehardshipsofdailyexistencehave givenrisetofraternalfeelingsandnon-communaltraditions.MembersofbothHinduandMuslimcommunitiesworship the same Gods and Goddesses, Gazis and Pirs" (Basu, 2006). The folklore of Bonbibi in The Hungry TideisagoodexampleofhowfaithandbeliefonthisGoddessprovidestheexemplarycouragetosustaininalandwherethe people of the land wake up to the roars of the Tigers. Banbibi (the lady of the forest), also Bandevi, Bandurgaand Byaghradevi is a guardian spirit of the forests venerated by both the Hindu and the Muslim residents of theSundarbans (spread across West Bengal state in eastern India and Bangladesh). She is called upon mostly by thehoney-collectors and the woodcutters before entering the forest for protection against the attacks from the tigers. Itis believed that the demon king, Dakkhin Rai (the lord of the south), an arch-enemy of Banbibi actually appears inthedisguiseofatigerand attackshuman beings.In"RiverofFire",QurratulHydermentionsinfootnotethat"Ban-Bibi" is Fatima, daughter of Prophet Muhammad and she is revered as the patroness of the woods by the forestdwelling MuslimsofBengal(Wikipedia contributors).

ThefaithinthisGoddessisthefactorthatconfirmsthecommonalityamongthepeopleintheTigerinfestedcoastalre gion."PiyastoodbyandwatchedasFokirandTutulperformedalittleceremony.Firsttheyfetchedsomeleaves and flowers... then standing before the shrine Fokir began to recite some kind of chant... Piya recognized arefrain that occurred over and over again... "Allah"" (Ghosh, 2004). Piya is confused to hear a Muslim chantcombined with Hindu Puja practice. Nirmal is surprised at the events that take place at the shrine. The shrine isnothing but a raised platform with bamboo sides and a thatched covering. They place the images of Bonbibi andShah Jongoli and Kusum lights fragrant dhoop and Fokir brings some leaves and flowers and leaves them at theirfeet.FollowedbythisHorenstartstorecite amantra inthefollowingwords.

Bismilahboliyamukheydhorinukalam/poidakorilojinnitamamalam*baromeherbantiniBandarupore*taarchhanikeba acheduniyarupore*

(In Allah's name, I begin to pronounce the Word / Of the whole universe, He is the Begetter the Lord* To all Hisdisciples, He isfullofmercy/Above thecreatedworld, whoistherebutHe*).(Ghosh, 2004)

Nirmal has been thinking that he is going to attend a Hindu Puja and all that he hears at the shrine is Arabicinvocations with rhythm of the recitation of a Hindu Puja. The language he hears is not chaste Arabic either, ablendofBangla,deeplyinterpenetratedbyArabicandPersian. ThenarrativeisjustthestoryofBonBibi'sencounterwith the demon Dokkin Rai. This style of recitation is passed mouth to mouth from one generation to the next andHoren hands over a book in which the recitation is printed. The title of the book is 'Bon BibirKaramotiorthat BonBibiJohuranama'(TheMiraclesofBonBibiorthenarrativeofHerGlory).Openingthebookelevateshissurprisesasthe pagesopentotherightasinArabicnotlikeBangla.TheauthorofthebookisaMuslimnamedAbdur-Rahim.It is pretty obvious that settlers have come in numbers to make a living and to all of them Bon Bibi has served astheprotectingdeityfromthe dangersofforestandtigers.

InTheRiverofSmoke, GhoshprovidesinterestingfactsaboutthedeitiesandtheguardianspiritofCanton.One day Zadig Bey using his spyglass introduces George Chinnery to the major landmarks in Canton. Chinnerylearns that the streets and lanes in Canton carry the reminders of Aliens. "WWhy,' he said, 'even the city's guardiandeityisaforeigner-

anAchhainfact"(Ghosh,2011)!Hecouldn'tbelievethat 'Canton'stutelaryspirit'isawomanwho was a sari clad woman once. There is a place which was once occupied by Buddhists from Hindusthan and aKashmiri monk named Dharamysa is famous among them. Down by the river is located a temple that was foundedby ofthe 
Dr.Sreela.B ${ }^{\mathrm{a}}$, Dr.SreejaBalakrishnan ${ }^{\mathrm{b}}, \mathrm{K}$.PoornimaVaralakshmi ${ }^{\mathrm{c}}$ and YaminiP ${ }^{\mathrm{d}}$

famousBuddhistmissionaries - the Bodhidharma, a nativeof Madras.

It is even more surprising to learn that the city also has one of the oldest temples in the whole world built in thelifetime of Prophet Mohammad. "It is a most remarkable structure, no different, in outward appearance, from aChinesetemple-allexceptfortheminaret, whichislikethatofanydargahinBengal”(Ghosh,2011)!Evenpeople 
who get converted from one religion to another carry some of the traits of their original culture and in such a waymodificationscreepingradually andbecome apartof customata laterpartof the time.

\section{Conclusion}

All the above-mentioned examples and incidents validates Jung's theories on archetype, as every character in hisnovel represents a sect and their actions and behaviour substantiates their collective unconscious. The recurringpatterns of the workings of the unconscious mind in humanity at moments of crises and other such circumstancesendorse each of these characters to be the prototypes of their society. All these characters belong to variednationalitiesandyettheirreticencetoacceptdefianceintheirconventionallifestyleremainsthesame. Ontheotherhan d,culturehasundergoneunfathomablechangeswheremindandthoughtsagaintakealion'sshareintheprocessof change. Although humans find differences unpalatable there are few psychological components that makedifferencesdesirableandpalatable.AmitavGhoshinhisnovelshasmadeconsiderablecontribution tothestudy ofcultureandchangesinculture. Hehasusedtheimaginarycharactersaswellasimaginarysituationsalongwithreallife characters and situations to depict the formation and changes in cultural patterns. The changes in cultural patternshavetakenplacechieflybecauseofthemeetingofculturesandthedesiretoestablishsociabilitywiththepeopleofdiff erentculture.

\section{Recommendations}

Based on the study, it is identified that cultural factors are always open to changes and it shall remain to be a neverending process. This study chiefly focuses on the works of Amitav Ghosh. The same novels can be studied for thepsychological implications of cultural changes. Similarly, novels of other authors can be studied employing thetheoriesofGeorgeSimmel.Acase-

studycanalsobeconductedtounderstandtowhatextentculturehasundergonechanges in the society. All such studies will prove to be beneficial in understanding the nuisances of culturalchanges.

\section{References}

1. Bastian, A (1983) The Waning of Primitive Societie.In: Koepping K-P(ed) Adolf Bastian and AdolfBastian and the Psychic Unity of Mankind: The Foundations of Anthropology in Nineteenth CenturyGermany. Australia:University ofQueenslandPress, 215-19.

2. Basu,RameshChandra,Dr.R.A.Khan,J.R.B.Alfred(eds)(2006)EnvironmentalAwarenessandWildlife Protection. Survey.222.

3. D'Andrade,R.G(1988)CulturalmeaningsystemsIn:R.A.Shweder,R.A.LeVine(eds.),Culturetheory:Essayso nmind, self,andemotion. Cambridge: CambridgeUniversity Press,Pp88-122.

4. Ghosh,A(1986)TheCircleofReason.NewDelhi:Penguin.

5. Ghosh,A(1988)TheShadowLines.NewDelhi:Penguin.

6. Ghosh,A(2000)TheGlassPalace.NewDelhi:Penguin.

7. Ghosh,A(2004)TheHungryTide. NewDelhi:Penguin.

8. Ghosh,A(2006)InanAntiqueLand.NewDelhi:RaviDayalPublisher

9. Ghosh,A(2008)SeaofPoppies.NewDelhi:Penguin.

10. Ghosh,A(2011)TheRiverofSmoke.NewDelhi:Penguin.

11. Giles, H, Vikki Katz, and Paul Myers (2006)Language Attitudes and the Role of CommunityInfrastructure: ACommunicationEcology. Availableathttp://vikkikatz.com/wpcontent/uploads/2014/01/giles-katz-myers-2006-language-attitudes-and-the-role-of-communityinfrastructure-moderna-sprak.pdf(accessed 2Nov.2014).

12. Habermas,J(1979).CommunicationandtheEvolutionofSociety,London:SAGEPublications.

13. Luke KK and Richards JC (1982) "English in Hong Kong: functions and status", English WorldWide, Vol3No.1, pp47-64.

14. MauraisJacquesandMichaelAMorris(2004)"Languagesin aGlobalisingWorld"'UK:CambridgeUniversityPress, pp1-5.

15. Simmel,G(1949)TheSociologyofSociabilitysubmittedtoAmerican JournalofSociologyVol55 No.3pp 254261.

16. SreelaB(2015) “MimicryofLanguageasa Play-FormofLifeintheSelectIndian Novels”IJELLH,Vol3 No.3, pp252-259.

17. Thompson,RH(1996)Assimilation.InEncyclopediaofSocialandCulturalAnthropology,NewYork:Henry HoltandCompany.

18. Winthrop,RH(1991)Dictionary ofConceptsinCulturalAnthropology.NewYork: Greenwood.pp 3

19. Wikipediacontributors. “Bonbibi.” Wikipedia,2Sept.2020,en.wikipedia.org/wiki/Bonbibi. 